\title{
Politique
}

Politique

\section{J. Yvon Thériault, La Société civile ou la chimère insaisissable, Montréal, Québec/Amérique, 1985, 160 p.}

\section{Jean-Guy Vaillancourt}

Numéro 15, hiver 1989

Paradigmes et scientificité

URI : https://id.erudit.org/iderudit/040630ar

DOI : https://doi.org/10.7202/040630ar

Aller au sommaire du numéro

Éditeur(s)

Société québécoise de science politique

ISSN

0711-608X (imprimé)

1918-6584 (numérique)

Découvrir la revue

Citer ce compte rendu

Vaillancourt, J.-G. (1989). Compte rendu de [J. Yvon Thériault, La Société civile ou la chimère insaisissable, Montréal, Québec/Amérique, 1985, 160 p.] Politique, (15), 140-143. https://doi.org/10.7202/040630ar d'utilisation que vous pouvez consulter en ligne.

https://apropos.erudit.org/fr/usagers/politique-dutilisation/ 
J. Yvon Thériault, La Société civile ou la chimère insaisissable, Montréal, Québec/Amérique, $1985,160 \mathrm{p}$.

L'ouvrage d'Yvon Thériault est une grande fresque qui traite de l'histoire du concept de société civile telle que celle-ci est perçue dans la tradition marxienne. L'auteur y centre son attention sur les sujets politiques et sur les mouvements sociaux non réductibles aux classes sociales et à l'État. Son cheminement part de Hobbes, de Locke et de Hegel, il s'attarde sur les idées de Marx, de Gramsci, et d'Habermas, pour conclure avec l'approche de Gorz, de Ronsanvallon et de Touraine en France. Le but de l'ouvrage n'est pas de replacer le concept de société civile dans l'histoire de la pensée, ni même chez l'un ou l'autre de ces auteurs, mais plutôt de faire un effort de compréhension de la dimension ethico-politique du social dans les théories étudiées.

Pour l'apologiste conservateur qu'est Hobbes, la société civile est le vaste lieu où s'opère le contrôle d'une nature humaine débridée. Pour Locke, la société civile contribue à régulariser et à actualiser une nature humaine qu'elle ne crée pas. Les philosophes Rousseau et Kant 
poussent le principe d'actualisation et d'auto-réalisation plus loin encore; ils appellent à un dépassement de la société civile de leur temps par une comparaison avec l'état naturel vu comme un idéal. Pour Ferguson et les historiens écossais de son époque, la société civile demeure quelque chose de politico-éthique, mais avec des économistes politiques comme Adam Smith, on passe graduellement de la dichotomie classique, état de nature/société civile ou politique, à la distinction plus moderne entre société civile et société politique, c'est-à-dire entre le social et l'économique d'une part, et le politique et l'idéologique d'autre part. Avec Smith et ces économistes politiques, on est passé d'une conception morale et juridico-politique du social à une conception nettement économiste, c'est-à-dire une conception qui fonctionne en termes de classes sociales et de marché. La morale et même le politique sont vus comme de simples dérivés de l'action économique, et le marché occupe toute la place dans la société civile.

Hegel prend note de ce glissement opéré par l'économie politique et par la pensée utilitariste. La société civile pour lui est le produit du déploiement de la raison dans l'histoire; elle est éminemment économique; elle est la sphère des besoins, le champ de bataille des intérêts égoïstes particuliers, l'espace coincé entre la famille et l'État, ce dernier servant à faire passer ces intérêts particuliers à un ordre plus élevé grâce à la lumière de la raison. En somme, la société civile, pour Hegel, présuppose l'État, alors que pour le jeune Marx, c'est le contraire qui est vrai: l'État est un dérivé de la société civile, qui est le moment premier. Marx remet donc Hegel sur ses pieds en affirmant la prééminence de la société civile sur l'État. Marx fait de l'État le prédicat et non le sujet. Dans La Question juive (1843), il affirme que l'émancipation du politique par rapport à la société civile ne mène pas à l'émancipation humaine. Le politique est alors théorisé comme une force de coercition au service des intérêts privés.

Marx en vint rapidement à remplacer la dichotomie société civile/État, par des distinctions entre infrastructure et superstructure, entre forces productives et rapports de production, et entre Capital et Travail. Il y a là une certaine réduction de la société civile à sa base économique et un rejet de l'importance propre des rapports politiques et culturels. Le social est réduit à l'économique, et le mode de production 
élimine la société civile. Dans le 18 Brumaire, et dans la lettre à Annenkov en 1846, Marx semble toutefois situer la société civile (c'est-à-dire la structure sociale) quelque part entre l'infrastructure économique et la superstructure politique et idéologique, bien que dans la préface de la Contribution à la critique de l'économie politique il affirme très clairement que «l'anatomie de la sociêté civile doit être recherchée à son tour dans l'économie politique». En somme, Marx fut vraiment, malgré ses velléités de jeunesse et ses protestations tárdives, un vrai marxiste, c'est-à-dire un déterministe économique. Entre la sphère des besoins (le mode de production) et la sphère politique (l'État), il n'y a vraiment pas de place pour la société civile comme entité autonome.

Korsch, Lukacs et Gramsci furent sensibles à la réaffirmation de l'importance de l'idéologie, c'est-à-dire des superstructures. Gramsci voit deux étages dans la superstructure; la société politique et la société civile, «la première fonctionne à la coercition, la seconde à l'hégémonie». Marx avait assimilé société civile et sphère des besoins, et lui avait substitué le concept d'infrastructure économique. Bobbio affirme que Gramsci situe plutôt la société civile hors de l'économique, dans la superstructure. Pour lui, l'ordre de prééminence serait idéologiepolitique-économique et non l'inverse comme chez Marx. Gramsci n'oppose pas la société politique à la société civile, mais voit la sociêté civile comme étant partie intégrante de l'État ou comme étant prééminente par rapport à l'État. Le concept d'hégémonie devient alors la façon par excellence de combattre l'économisme de certains marxistes soi-disant orthodoxes. La société civile est le reflet des classes sociales au niveau culturel, mais elle a son fondement dans la production matérielle, c'est-à-dire dans les classes sociales.

Le chapitre IV s'inspire d'Habermas qui distingue les modalités d'intégration reliées aux processus de production (le travail) et les modalités d'intégration reliées aux processus de socialisation (l'intéraction). La modernité a établi la préminence des logiques rationnelles sur les logiques communicationnelles, et elle a fait éclater ces dernières, amenant par le fait même la reconnaissance d'une société civile. Les nouveaux mouvements sociaux remettent en question ce caractère préminent des conflits liés au procès de production sur ceux 
qui sont liés au procès de socialisation, caractère prééminent que l'on rencontre aussi dans le projet socialiste.

La conclusion de l'ouvrage tente de poser des hypothèses fragmentaires sur les conséquences politiques d'une prise en compte des passions que l'on trouve dans la société civile, au plan des possibilités du développement de la démocratie, grâce à l'apport des mouvements sociaux. L'auteur montre comment cette chimère insaisissable qu'est la société civile est le terrain de prédilection de l'éthique et de la démocratie. En somme, Thériault aboutit à une position assez proche de celle d'Alain Touraine: réfléchir sur la construction d'un large mouvement démocratique basé sur l'autonomie des mouvements sociaux et chercher l'axe central qui guide la démarche de ces mouvements sociaux pour définir les forces de changement et dégager l'axe de la démocratie. Thériault, toutefois, insiste plus que ne le fait Touraine sur la nécessité d'analyser la structure du pouvoir.

En définitive, l'ouvrage de Thériault scrute, de façon complexe mais quand même intéressante, l'histoire du concept de société civile, pour aboutir à des réflexions fort pertinentes sur la démocratie et sur l'approche en termes des nouveaux mouvements sociaux, approche qui représente actuellement ce qu'il y a de plus dynamique, à mon avis, dans la pensée sociologique française contemporaine, suite à la déconfiture de l'althussérisme et du poulantzassisme. Espérons que dans ses prochains ouvrages, Thériault poursuivra son effort de théorisation dans ces domaines, mais sur une base plus sociologique, et qu'il remplira le canevas de travail que son excellent petit essai a esquissé.

Jean-Guy Vaillancourt Université de Montréal 